\title{
Minneord om Asle Bruen Olsen $(1951-2018)$
}

Asle ble brått revet bort fra oss på en av de varme sommerdagene nå i juli. Budskapet om hans bortgang var uventet og brutalt. Det kom et mørke i denne soldagen som ennå sitter i. Asle av alle. Det altoppslukende engasjementet, iherdigheten, betydningen av det han fikk til, vennskapet, vitetrangen, rausheten i delte nyvinninger, kunnskap og erfaring, staheten; det burde holdt til hundre år mere på jorda. Men slik ble det ikke. På ny blir vi minnet om dødens vilkårlighet. Rettferdighet og rimelighet er absurde størrelser når det gjelder hvem som får bli i verden. Å skrive minneord om Asle kjennes meningsløst og meningsfylt på samme tid.

Asle ble født i Trondheim, og han fikk sine første erfaringer fra arkeologisk feltarbeid i det trønderske kulturlandskapet. Han deltok i utgravningene i Trondheims bygrunn, Folkebibliotektomten, og var på god vei mot middelalderstudier. Han videreførte sin arkeologiske interesse ved Universitetet i Bergen (1972), og ble etter hvert penset mot steinalderstudier. Han avsluttet sin magistergrad i 1981. Avhandlingen var et omfattende nybrottsarbeid om brudd og bruk av diabas fra Stakaneset i nærheten av Florø. Avhandlingen vokste frem i par med Sigmund Alsakers arbeid om bergartsbrudd i Sunnhordland, på Hespriholmen og Siggjo. Til sammen ble de to avhandlingene en skjellsettende studie av steinalderens bruk og distribusjon av råstoff, som åpnet opp et nytt felt i steinalderstudiene i Sør-Norge. De to arbeidene ble føyd sammen i en artikkel i Norwegian Archaeological Review (Olsen og Alsaker 1984), som fremdeles er en pilar i norsk steinalderforskning.

Etter studiene ventet nye feltprosjekter, Botnaneset utenfor Florø, Kotedalen ved Fosnstraumen, Skatestraumen i Nordfjord sammen med Knut Andreas Bergsvik. Til sammen ga disse og andre mindre prosjekter et detaljert innsyn i steinalderens samfunn som gikk mot økt bofasthet og begynnende jordbruk. Asle fremhevet variasjoner i livbergingsform som ga seg til uttrykk i mer enn tradisjonelle redskapstyper. Asle pekte på tydelige endringer i boplassmønsteret, både med hensyn til boplasstyper og lokalisering. Hva som var optimale bosteder endret seg med variasjonene i næringsmønster, var et av Asles poenger.

Feltstudier er en rød tråd gjennom hele hans virke, og nye data derfra har vært avgjørende for skiftninger i Asles interessefelt. Hans gode nese for kunnskapspotensialet i feltprosjektene medførte at han våget seg inn på andre forskningsfelt. Det som i utgangspunktet 


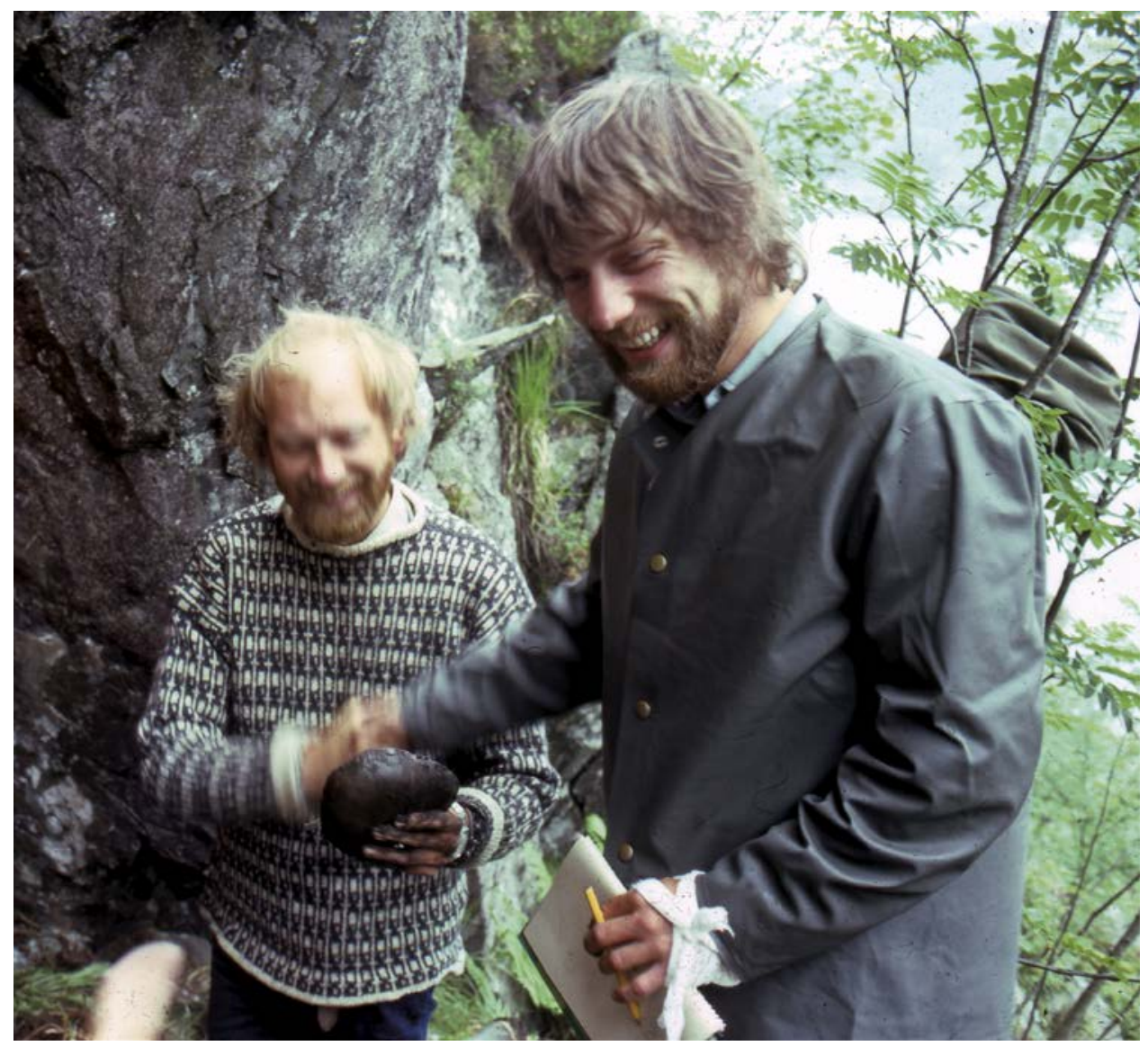

Figur 1. I dette øyeblikket (1977) ble det klart at diabasforekomsten i Stakaneset var et bergartsbrudd fra steinalderen - et skjellsettende øyeblikk for Asle, og ikke minst for norsk steinalderforskning. Det definitive beviset var denne store «knakkesteinen» som ble funnet dypt nede i massen av trekull og ildskjørnet stein i diabasgangen. Her gratuleres Asle av Tore Bjørgo, de to arbeidet tett under studietiden. I stunden var dette en betydelig seier for Asles magistergradsprosjekt, men dimensjonene i oppdagelsen visste vi lite om den gang. Nå, 40 år senere, røres jeg også av den improviserte bandasjeringen av Asles venstre hånd - et minne om den iherdigheten og evnen til å se smått på hindringer som kjennetegnet Asle. Foto: Hein B. Bjerck.

var en samling kokegroper i Stryn, ble utviklet til et viktig arbeid om ringtun i vikingtid. Nok et heldig funn på Sausjord ved Voss fra eldre jernalder ga nye data i samme retning, og arbeidene som fulgte viser tydelig Asles evne til å gå i dybden på nye områder. Nyoppdagelsene og gamle funn ble sammenføyd i en diskusjon om ringtunenes struktur, funksjon og rolle - i retning av at det ikke var gårdsbruk, men viktige samlingsplasser i jernalderens maktstruktur. Et overraskende funn av smedverktøy under en helle i Indre Sogn avfødte en innsiktsfull diskusjon om smeden i vikingtid. ${ }^{1}$ Entydige funn fra et mangesidig og spesiali- 
sert håndverk fra vikingtid på et uventet sted, Bjørkum i Lærdal, har vekket interesse i internasjonalt fagmiljø. Studiene favnet mange samarbeidspartnere, som finstemt balanserte Asles faglige raushet og respekt for andres kompetanse; se litteraturlisten for en oversikt over hans viktigste arbeider.

Feltstudier var kjernen i Asles tilnærming til arkeologien. Alle hans arbeider tilkjennega forkjærligheten til nye data, kvalitetssikring, presis datering, naturvitenskapelige analyser og målrettede stikkprøver - sammen med en egen sans for gode problemstillinger. Som erfaren feltarkeolog var det neppe tilfeldig at Asle i 2004 ble leder for den nyopprettede Seksjon for ytre kulturminnevern ved Historisk Museum, Universitetet i Bergen, som han ledet til sin dødsdag. Her fikk han til fulle bruk for sine brede kulturhistoriske kunnskaper, sin evne til å formulere problemstillinger og lage prosjektdesign og -budsjett, tverrfaglige analyser og synteser. Utgravningsprosjektene som falt inn i dette arbeidsfeltet var i stor grad styrende for hans faglige fokus og forskernettverk.

Asles publikasjoner er på mange vis et godt eksempel på skiftningene i de siste tiårenes utvikling av faget. Røttene i ny-arkeologiens idealer er tydelige. Mange har publisert mer enn Asle, drevet frem videre teoretiske perspektiver, gått dypere inn i detaljene. Færre kan fremvise forskning med en så tydelig og bred regional kulturhistorisk forankring, i så stor grad basert på nye data fra ferske feltundersøkelser, kombinert med resonnementer mot det overordnede.

Asle fremstilte seg aldri for doktorgraden, men da han ble vurdert til kompetanseopprykk i 2013, ble hans samlede produksjon vurdert til doktorgrad, med god margin. Jeg tar sjansen på å sitere fra komitéinnstillingens konklusjon, som er godt dekkende for Asles faglige kvaliteter:

Arbeidene Asle Bruen Olsen har lagt frem som grunnlag for kompetansevurdering viser både bredde og kvalitet. Gjennomgående er de basert på komplekse studier med solid empirisk forankring, oftest ferske feltundersøkelser som har brakt for dagen nye og interessevekkende data. Olsen viser beundringsverdig evne og vilje til å se nye resultater i sammenheng med overregional kulturhistorie og aktuelle problemstillinger. Arbeidene fremviser stor materialkunnskap, teoretisk oversikt og metodisk stringens, og evner å trekke det hele sammen til konklusjoner som flytter forskningsfronten. Med seig energi har Olsen også maktet å tilføre kulturminnevernet mange av disse verdiene.

Denne soliditeten gir seg utslag i at mange av Olsens arbeid står seg godt over tid, og er gjengangere på pensumlister og som referanser i vitenskapelige artikler. Den omfattende og originale forskningen omkring steinalderens steinbrudd på Vestlandet er et godt eksempel: Den systematiske tilnærmingen til å lokalisere og undersøke selve diabasbruddet, samt den påfølgende analysen av bruddstedet og steinens store betydning i steinalderens samfunn gjennom 6-7000 års økseproduksjon er imponerende. Fra et tradisjonelt typologisk-teknologisk utgangspunkt forgreiner studiet seg til geologiske analyser av steinbrudd og proveniensbestemming av økser, som tegnet vidstrakte distribusjonsnett - og nye og vesentlige perspektiver på steinalderens samfunnsorganisering og forestillingsverden. Vi nøler ikke med å plassere denne studien og dette arbeidet blant de viktigste innenfor norsk arkeologisk forskning.

At dette arbeidet aldri er underkastet en høyere formell akademisk vurdering beror på tilfeldigheter. Både omfang og kvalitet i analysen, samt fremstillingens klarhet, grundighet, originalitet og arbeidets store forskningsmessige betydning tilsier at det kun er mindre justeringer og formkrav som skiller Olsens magistergradsavhandling fra en doktorgrad. (Komitéuttalelse av 20.9.2013, Arne B. Johansen, Inger Storli og Hein B. Bjerck) 


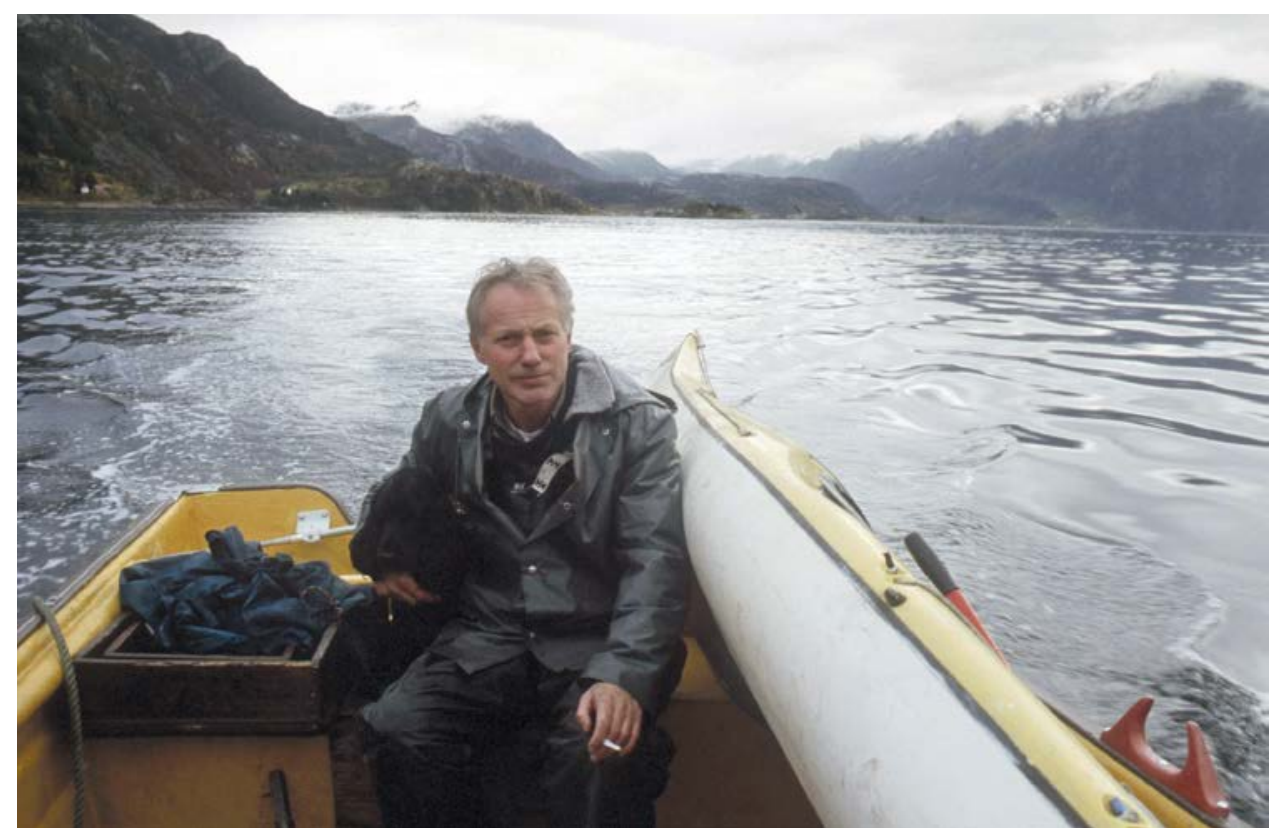

Figur 2. Asle i en stille stund på fjorden under Skatestraumenprosjektet i Nordfjord, 1991. Foto: Knut Andreas Bergsvik.

Dødens klo kan ikke løsnes, men savnet etter Asle dulmes i så mange minner som er gode. Jeg røker sakte en sigarett (Asle mente jeg burde slutte, sist vi møttes) og tenker på tiårene vi hadde sammen. Det er noe eget med arkeologifaget, det holdes sammen av et nettverk som baserer seg like mye på vennskap og samarbeidsevner som på faglighet. Vi er ikke så mange, og båndene vokser naturlig frem allerede under studietiden. Under feltarbeidene hersker et faglig engasjement som smelter sammen med et praktisk-sosialt fellesskap og etablerer tette forbindelser. Ofte er båndene langvarige. Sammen må vi bli enige om romfordeling der vi skal bo, pølser eller fisk til middag, «kostøre». Vi drikker øl og diskuterer det vi nyss har fravristet muldens mørke, med et engasjement like intenst som etter en seier i lagidretten. Fellesskap favner gode soldager, mygg og gjørme, heldige funn, sammenlikning av flåttbitt. Sammen feirer vi dateringer som spikrer dristige antakelser, og analyser som sementerer luftige synteser, summering av data som viser sammenhenger som ikke lenger er synlige, overraskende prøvestikk og avklarende sjakter. Vi diskuterer like godt (eller kanskje bedre) i bilen og i kaffepauser i felt som under seminarene. Det var i denne veven jeg kjente Asle. Et arbeidsjern som ofte måtte minnes om lunsjpause og arbeidstidens slutt. Oljeklær som aldri var nye, en sydvest som var for liten, en gammel genser med for lange ermer. Den litt kneggende latteren som alltid satt løst. Men også klare meninger om det meste, som kunne strekke seg mot det stridbare.

Det faglige nettet næres av møter, seminarer og konferanser, ekskursjoner og befaringer i det videre arbeidslivet. Jeg minnes Asles vel forberedte konferanseinnlegg. Han hadde så mye på hjertet, margene i maskinskrevne manus var fylt med innskudd han måtte huske å få 
med. «Fem minutta? Nei, det går itj», var hans enkle svar da ordstyrer viste lappen på en konferanse nå nylig. Asle fikk holde på til han var ferdig.

Det var så mange sider i magistergradsavhandlingen, altfor mange. Asle slanket den ved å unnlate å paginere illustrasjonssider. «Figurene har jo egne nummer.» En velrenommert forsker kom helt fra Australia for å se grønnsteinsbruddet på Hespriholmen sammen med Asle og Sigmund. Fergen var i ferd med å forlate kaien, men Asle speedet opp sin banangule Simca, fløytet og blinket med lysene. De kom seg med, men oppdaget etter 50 meter at det var feil ferge. Den uforutsette omveien la en ekstra opplevelse til turen, som den australske gjesten sikkert ennå husker med glede. På vei til feltarbeid på Orknøyene trillet venstre framhjul først inn på ferga, Asle var blitt heftet med noe annet under hjulskiftet. På pub i Belfast under Mesolithic in Europe-konferansen: flere av gjestene ville la seg fotografere sammen med Asle påsatt briller. De synes han lignet på «Svennis», som den gang trente det engelske fotballandslaget.

Jeg møtte Asle på utgravning ved Brandsøysund i 1975 ved Florø, mitt hjemsted, jeg skulle begynne å studere arkeologi den høsten. Læringskurven var stupbratt. Asle lærte meg fenomenet «slagbule», selve nøkkelen til et sikkert møte med steinalderen. Å være på innsiden av denne ekspertkunnskapen ga et faglig løft, det var et kvantesprang. I iveren skrev jeg innlegg i Firda Folkeblad om innsikten, det var som en misjonsgjerning. Det var ett av arkeologifagets mysterier, hvordan skille ut tingene som bar minner fra selveste steinalderhånden. Asle syntes kanskje han fikk dårlig betalt for å dele denne innsikten, i alle fall gjorde han ingen forsøk på å skjule irritasjonen da jeg etter noen måneders studium antydet at noen av de grovhogde økseemnene minnet om paleolittiske håndkiler. Ikke lenge etter kom en ny tabbe. På en tur til strendene langs Brandsøysund for å nyte synet av kurvaturen i fete slagbuler i mengden av diabasartefakter oppdaget jeg at noen av dem var malt knall røde. Som god arkeologspire samlet jeg dem opp og undret meg: Hvem kunne ha gjort dette? Uansett måtte det fortelles til Asle. Samlingen av røde avslag var blitt ganske stor før jeg kom i tanker om at det kunne være Asle selv, at rødfargen var ledd i noe vitenskapelig. Ganske riktig. Da Asle fikk høre om «oppdagelsen» noen dager senere, ville han straks vite om jeg hadde flyttet på røde avslag. Joda, noen få. «Men jeg flyttet ikke på alle», la jeg til for å dempe tabben. Det hjalp ikke, hele eksperimentet var tilrotet. Asle hadde nemlig en plan med det hele, han ville undersøke hvordan bølgene flyttet partikler i stranden, om artefaktene der var vasket ned fra høyere nivå.

Det var et forsøk i tidens ånd, ny-arkeologien. For Asle var det ikke nok å mene, han ville dokumentere, teste, vitenskapeliggjøre. Synsing hørte ikke hjemme på innsiden av faget. Små bevis ville etter hvert tette hullene i kunnskapsteppet som vi sammen vevde. Egenhendig hadde han dyppet avslagene i rødmaling, tørket dem og plassert dem på stranden i et sinnrikt system der alle som én var posisjonert med to desimaler. Men han hadde oversett den viktigste grunnen til at ting flytter seg i fjæra; sunnfjordsk klåfingring, som vanligvis måles mer i meter enn i millimeter. Så lærte vi kanskje begge noe av dette; for Asle bristeferdigheten i små bevis - jeg å tenke før man tukler.

Vittige ubetydeligheter og ablegøyer, men også hendelser som kjennetegner Asle, og som var avgjørende for å smøre og vedlikeholde nettverkene som er arkeologifaget. Alltid var han omgitt av lett kaos, som han håndterte både kreativt og sikkert - Asle kom ned på beina uten tap av handlekraft der de fleste ville ha snublet. Man kunne velge å la seg irritere, men på den andre siden av Asles «uorden»var raushet, romslighet og artige episoder. Det 


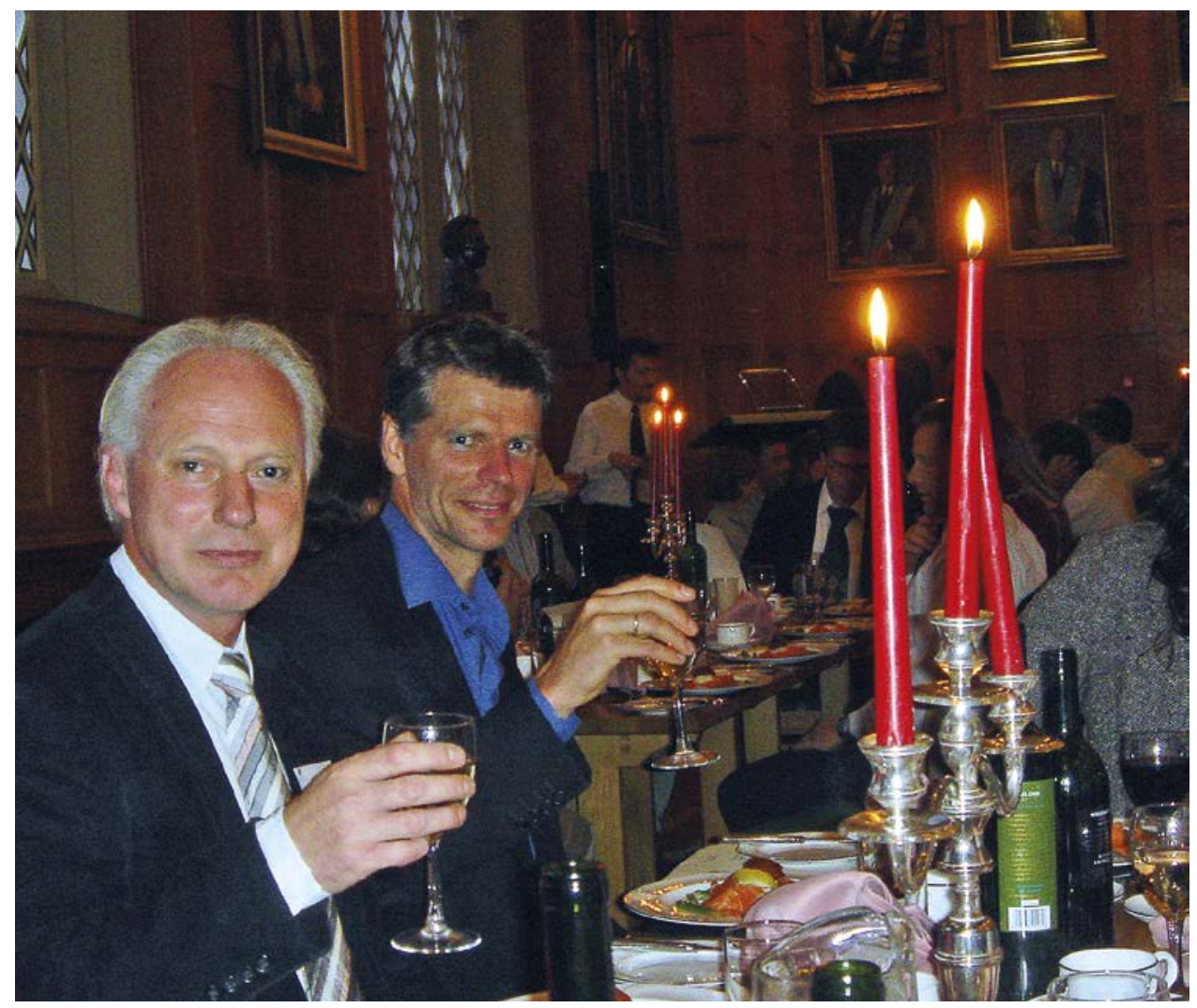

Figur 3. Asle og Knut Andreas Bergsvik under banketten på Mesolithic in Europe-konferansen i Belfast, 2005. Foto: Hein B. Bjerck.

var kanskje en viktig grunn til at Asle var så godt likt langt utenfor kretsen av fagfeller, langt inn i rekkene av utbyggere, entreprenører, planleggere og journalister, folk flest. Asle mestret og trivdes i arkeologifagets vidstrakte nettverk. Som edderkoppen var han en samlingsfigur, han visste hvordan nettet måtte forankres og struktureres, han kjente klebrige tråder fra dem han kunne løpe langs, og han sanset de ørsmå vibrasjonene som varslet om arkeologisk gevinst.

\section{Takk}

Takk til Thomas Bruen Olsen og Knut Andreas Bergsvik for innspill til minneordet.

\section{Note}

1 Se artikkelen i denne utgaven av Viking: Randi Barndon og Asle Bruen Olsen «En grav med smedverktøy fra tidlig vikingtid på Nordheim i Sogndal. En analyse av gravgods, handlingsrekker og symbolikk». 


\section{Litteratur}

Barndon, Randi og Asle Bruen Olsen

2017 Nordheimgraven i Sogndal. Smedgrav eller grav med smedutstyr? Konferanseinnlegg, Fortidens teknologi og samfunn - kunnskap og formidling, Trondheim 17.03.2017. NTNU Vitenskapsmuseet, Trondheim.

Barndon, Randi, Asle Bruen Olsen og Howell M. Roberts

2015 An extraordinary Viking-age grave with smithing tools from Nordheim in Sogndal, Western Norway. Konferanseinnlegg, Exploring the middle ages, 25.-27. november 2015, Universitetet i Bergen, Bergen.

2016 Smithing Tools as Buried Things - A presentation of an early Viking-age grave from Nordheim, Sogndal in Western Norway. Konferanseinnlegg, Buried Things - Recent discoveries of Viking graves in Iceland and Norway. 21.-22. januar 2016, Reykholt.

Bergsvik, Knut Andreas og Asle Bruen Olsen

2000 Task Groups and Exchange Networks in Mesolithic Western Norway. Konferanseinnlegg, 6th International Conference on The Mesolithic in Europe, Nynäshamn, Sverige.

2003 Traffic in Stone Adzes in Mesolithic Western Norway. I Mesolithic on the Move, redigert av Lars Larsson, Hans Kindgren, Kjel Knutsson, David Loeffler og Agneta Åkerlund, s. 395-404. Oxbow Books, Oxford.

Bergsvik, Knut Andreas, Asle Bruen Olsen, Lene Synnøve Halvorsen og Kari Loe Hjelle

2017 The slow neolithization: a case-study from Western Norway. Konferanseinnlegg, 23rd European Association for Archaeologists annual meeting, Maastricht.

Bjerck, Lisa Bostwick og Asle Bruen Olsen

1983 Kulturhistoriske undersøkelser på Botnaneset, Flora 1981 - 1982. Fangstbosetning og tidlig jordbruk $i$ steinalder/bronsealder. Arkeologiske avhandlinger og rapporter fra Universitetet $\mathrm{i}$ Bergen, vol. 5. Historisk museum, Universitetet i Bergen, Bergen.

Heide, Eldar og Asle Bruen Olsen

2012 Sola gjer ekstranummer. Bergens Tidende 24. juni 2012:27. Bergen.

Hjelle, Kari Loe, Anne Karin Hufthammer, Peter Emil Kaland, Asle Bruen Olsen og Eli Christine Soltvedt

1992 Utnytting av naturressursene i Kotedalen - et tverrvitenskapelig sammendrag. I Kotedalen - en boplass gjennom 5000 år. Bind 2: Naturvitenskapelige undersøkelser, redigert av Kari Loe Hjelle, Anne Karin Hufthammer, Peter Emil Kaland, Asle Bruen Olsen og Eli Christine Soltvedt, s. 139-150. Historisk museum, Universitetet i Bergen, Bergen.

Hjelle, Kari Loe, Anne Karin Hufthammer, Peter Emil Kaland, Asle Bruen Olsen og Eli Christine

Soltvedt (red.)

1992 Kotedalen - en boplass gjennom 5000 år. Bind 2: Naturvitenskapelige undersøkelser. Historisk museum Universitetet i Bergen, Bergen.

Kazakievicius, Vytautas, Asle Bruen Olsen og David Simpson (red.)

1998 The Archaeology of Lithuania and Western Norway: Status and perspectives. Archaeologia Baltica, vol. 3. Lithuanian Institute of History Vilnius, Vilnius.

Olsen, Asle Bruen

1977 Grønnsteinsindustri i Sunnfjord i steinalderen. Arkeo 1977:11-14.

1978 En tidligmesolitisk flintplass. Arkeo 1978:31-35.

1981 Bruk av diabas i vestnorsk steinalder. Upublisert Mag. Art. avhandling. Historisk Museum, Universitetet i Bergen, Bergen.

1988 Økonomisk tilpasning i vestnorsk yngre steinalder. Status og perspektiver. I Festskrift til Anders Hagen, redigert av Svein Indrelid, Sigrid H. Kaland og Bergljot Solberg, s. 242-251.

Arkeologiske skrifter, vol. 4. Historisk museum, Universitetet i Bergen, Bergen.

1992a Kotedalen - en boplass gjennom 5000 år. Bind 1: Fangstbosetning og tidlig jordbruk $i$ vestnorsk steinalder: Nye funn og nye perspektiver. Historisk museum, Universitetet i Bergen, Bergen.

1992b Yngre steinalder i Kotedalen. Arkeo 1992(1):21-25. 
1993 Sedentisme og jordbrukspraksis i vestnorsk fangststeinalder belyst ved de tverrvitenskapelige undersøkelser i Kotedalen, Nordhordland. Konferanseinnlegg, Steinalderkonferansen i Bergen, 25.-27. mars 1993, Bergen.

1995 Fangstsedentisme og tidlig jordbrukspraksis i vestnorsk yngre steinalder belyst ved undersøkelsene i Kotedalen, Radøy, Hordaland. I Steinalderkonferansen i Bergen 1993, redigert av Knut Andreas Bergsvik, Signe Nygaard og Arne Johan Nærøy, s. 131-150. Arkeologiske Skrifter, vol. 8. Historisk museum, Universitetet i Bergen. Bergen.

1998a Preface. I The Archaeology of Lithuania and Western Norway: Status and perspectives, redigert av Vytautas Kazakievicius, Asle Bruen Olsen og David Simpson, s. 7-18. Archaeologia Baltica, vol. 3. Lithuanian Institute of History Vilnius, Vilnius.

1998b Lituania and Western Norway in the Neolithic period: Research goals derived from comparative presentation of two «marginal» regions in Neolithic Europe. I The Archaeology of Lithuania and Western Norway: Status and perspectives, redigert av Vytautas Kazakievicius, Asle Bruen Olsen og David Simpson, s. 43-54. Archaeologia Baltica, vol. 3. Lithuanian Institute of History Vilnius, Vilnius.

2005 Et vikingtids tunanlegg på Hjelle i Stryn - en konservativ institusjon i et konservativt samfunn. I Fra funn til samfunn. Jernalderstudier tilegnet Bergljot Solberg på 70-årsdagen, redigert av Knut Andreas Bergsvik og Asbjørn Engevik, s. 319-355. UBAS, Universitetet i Bergen Arkeologiske Skrifter. Nordisk, vol. 1. Arkeologisk institutt, Universitetet i Bergen, Bergen.

2009 Transition to farming in western Norway seen as a rapid replacement of landscapes. I Mesolithic Horizons. Papers presented at the Seventh International Conference on the Mesolithic in Europe, Belfast 2005, redigert av Sinéad McCartan, Rick J. Schulting, Graeme Warren og Peter C. Woodman, s. 588-596. Oxbow Books, Oxford.

2012 Neolittiseringen av Vestnorge. Møtet mellom to historiske tradisjoner i MNB. I Nordlige Verdener. Agrarsamfundenes ekspansion i nord, redigert av Flemming Kaul og Lasse Sørensen, s. 125-141. Nationalmuseet, København.

2013a Jordbrukskulturens pionertid på Vestlandet. Hus, åker og territorialitet. I Jordbruksbosetningens utvikling på Vestlandet. Seminar om dagens kunnskapsstatus, presentasjon av nye resultater og fremtidige problemstillinger, redigert av Søren Diinhoff, Morten Ramstad og Tore Slinning, s. 129-148. Universitetet i Bergen Arkeologiske Skrifter. Nordisk, vol. 7. Arkeologisk institutt, Universitetet i Bergen, Bergen.

2013b Undersøkelsen av et eldre jernalders tunanlegg på Sausjord, Voss, Hordaland: et nytt bidrag til kunnskapen om jernaldersamfunnets sosiale og politiske organisasjon. Viking 76:87-112.

2014 MNB på Vestlandet. Konferanseinnlegg, Seminar til Svein Indrelid 4.-5. desember 2014. Historisk museum, Universitetet i Bergen, Bergen.

2015 Courtyard sites in Western Norway. Central Assembly Places and judicial institutions in the Late Iron Age. I Viking Worlds. Things, Spaces and Movement, redigert av Marianne Hem Eriksen, Unn Pedersen, Bernt Rundberget, Irmelin Axelsen og Heidi Lund Berg, s. 43-55. Oxbow Books, Oxford.

2017 Når begynner historien om jordbruket og jordbrukerne på Vestlandet? Konferanseinnlegg, Steinalderkonferansen i Bergen, 21.-23. mars 2017, Universitetet i Bergen, Bergen.

Olsen, Asle Bruen og Sigmund Alsaker

1984 Greenstone and Diabase Utilization in the Stone Age of Western Norway: Technological and Socio-cultural Aspects of Axe and Adze Production and Distribution. Norwegian Archaeological Review 17(2):71-103.

Ramstad, Morten, Lene Synnøve Halvorsen og Asle Bruen Olsen

2011 Bjørkum: feasting, craft production and specialisation on a Viking Age rural site in Norway. Antiquity 85. Elektronisk dokument, www.antiquity.ac.uk/projgall/ramstad328, besøkt 3 . september 2018. 